\title{
Review \\ The Importance of Digging into the Genetics of SMN Genes in the Therapeutic Scenario of Spinal Muscular Atrophy
}

\author{
Mar Costa-Roger ${ }^{1,2} \mathbb{D}$, Laura Blasco-Pérez ${ }^{1,2}$, Ivon Cuscó ${ }^{1,2,3}$ and Eduardo F. Tizzano ${ }^{1,2, *}$ \\ 1 Medicine Genetics Group, Vall d'Hebron Research Institute (VHIR), 08035 Barcelona, Spain; \\ mar.costa@vhir.org (M.C.-R.); laura.blasco@vhir.org (L.B.-P.); icusco@vhebron.net (I.C.) \\ 2 Department of Clinical and Molecular Genetics, Hospital Vall d'Hebron, 08035 Barcelona, Spain \\ 3 Centro de Investigación Biomédica en Red de Enfermedades Raras (CIBERER), 08035 Barcelona, Spain \\ * Correspondence: etizzano@vhebron.net; Tel.: +34-93274600 (ext. 6945)
}

Citation: Costa-Roger, M.;

Blasco-Pérez, L.; Cuscó, I.; Tizzano,

E.F. The Importance of Digging into the Genetics of SMN Genes in the Therapeutic Scenario of Spinal Muscular Atrophy. Int. J. Mol. Sci. 2021, 22, 9029. https://doi.org/ $10.3390 /$ ijms 22169029

Academic Editor: Merlin G. Butler

Received: 28 July 2021

Accepted: 19 August 2021

Published: 21 August 2021

Publisher's Note: MDPI stays neutral with regard to jurisdictional claims in published maps and institutional affiliations.

Copyright: (c) 2021 by the authors. Licensee MDPI, Basel, Switzerland. This article is an open access article distributed under the terms and conditions of the Creative Commons Attribution (CC BY) license (https:/ / creativecommons.org/licenses/by/ $4.0 /)$.

\begin{abstract}
After 26 years of discovery of the determinant survival motor neuron 1 and the modifier survival motor neuron 2 genes (SMN1 and SMN2, respectively), three SMN-dependent specific therapies are already approved by FDA and EMA and, as a consequence, worldwide SMA patients are currently under clinical investigation and treatment. Bi-allelic pathogenic variants (mostly deletions) in SMN1 should be detected in SMA patients to confirm the disease. Determination of SMN2 copy number has been historically employed to correlate with the phenotype, predict disease evolution, stratify patients for clinical trials and to define those eligible for treatment. In view that discordant genotype-phenotype correlations are present in SMA, besides technical issues with detection of SMN2 copy number, we have hypothesized that copy number determination is only the tip of the iceberg and that more deepen studies of variants, sequencing and structures of the SMN2 genes are necessary for a better understanding of the disease as well as to investigate possible influences in treatment responses. Here, we highlight the importance of a comprehensive approach of SMN1 and SMN2 genetics with the perspective to apply for better prediction of SMA in positive neonatal screening cases and early diagnosis to start treatments.
\end{abstract}

Keywords: spinal muscular atrophy; survival motor neuron 1; survival motor neuron 2; genotype-phenotype correlations; variants; hybrid structure

\section{SMA Is a Disease of Two Genes, a Determinant SMN1 and a Modifier SMN2}

Spinal muscular atrophy (SMA) is a severe neuromuscular disease characterized by progressive proximal muscle weakness and atrophy as a result of alpha neuron degeneration and irreversible loss in the spinal cord anterior horn [1]. Overall estimated incidence is 1 in 11,000 live births with a carrier frequency around 1/54 [2]. Despite SMA clinically manifests as a continuum, based on age of onset, achieved motor milestones and clinical severity, SMA patients are divided into type 0-IV ranging from very severe congenital forms with short life expectancy due to respiratory failure at birth to adult-onset patients maintaining the ability to walk $[3,4]$.

At the molecular level, SMA is an autosomal recessive disorder caused by loss of survival motor neuron 1 (SMN1, OMIM \#600354) gene in the 5q13 locus [5]. Around 95\% of cases are explained by homozygous deletion or gene conversion, while a minority of patients are compound heterozygous including intragenic pathogenic variants and deletion of one SMN1 allele [6].

Besides SMN1 gene there is SMN2 (OMIM \#601627), an almost equal centromeric paralog gene. Both $S M N$ genes have an identical genomic organization consisting of nine exons interrupted by eight introns, which fits with the recent duplication of the SMN1 gene, explaining why SMN2 is only present in humans $[5,7,8]$. The exact structure of the SMA region remains unclear and initially $S M N 1$ and $S M N 2$ were described to be in opposite directions (head-to-head) [5], but more recently, evidence supports that the two genes are 
oriented in the same direction [9]. More studies are needed to determine which structure is correct or if both orientations are present in the population.

Given that SMN2 was originated from SMN1, their sequences only differ in 16 paralogous sequence variants (PSVs), which represent a total of 20 different nucleotides between both genes (15 SNVs and 1 indel) [10] as represented in Figure 1. The PSV c.840C $>$ T, located in exon 7, causes exon skipping in the majority of SMN2 pre-mRNA transcripts resulting in a truncated, nonfunctional and rapidly degraded protein that is not able to oligomerize (SMN- $\Delta 7$ ) [11] and can only produce the complete functional protein in $10-15 \%$ of cases [12-14]. Conversely, SMN1 gene produces virtually full-length mRNA transcripts encoding the normal SMN protein. Bi-allelic alteration of SMN1 is the rule to confirm SMA, however SMN2 copies varying from 1 to 5 are present in all patients, as absence of both genes has never been reported in humans. An inverse correlation between SMN2 copy number (SMN2_CN) and disease severity is currently accepted, being the number of SMN2 copies the main modifier of the SMA phenotype (see Section 2) $[5,15]$.

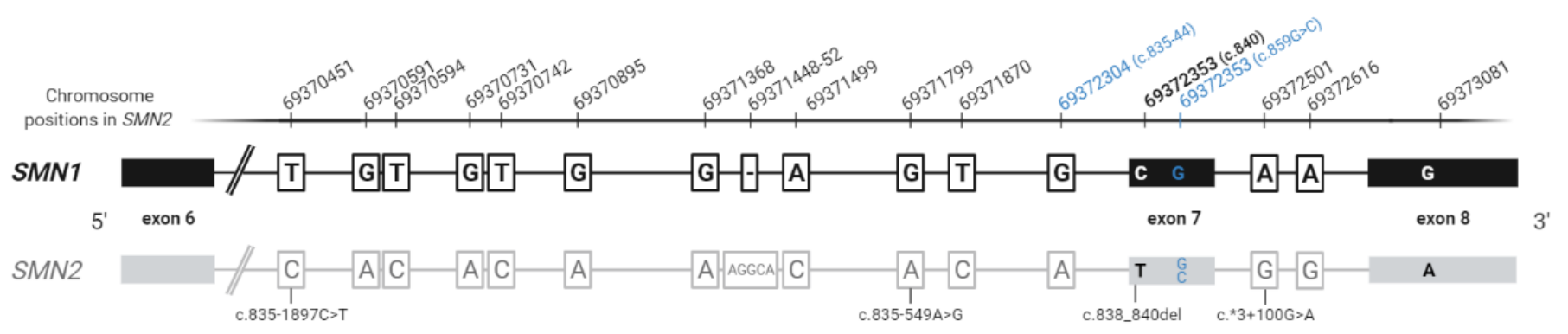

Figure 1. Schematic view of paralogous sequence variants (PSVs) between SMN1 and SMN2. PSVs are represented in black in SMN1 and in grey in SMN2 and validated positive modifiers (c.835-44A $>$ G and c.859G $>C$ ) in blue. The PSV that changes the splicing pattern of SMN2 (c.840C >T) is highlighted in bold. Putative SMN2 modifiers are indicated below the SMN2 scheme. Note that c.859G>C is not a PSV, but a rare variant present only in SMN2 gene. Chromosome positions in SMN2 refer to hg19. Based on reference [10].

The SMA genomic region is highly polymorphic and dynamic, which is prone to unequal rearrangements leading to deletions, duplications or gene conversions [7]. In fact, the presence of $S M N 1$ or $S M N 2$ genes lacking exons 7 and 8 (SMN1/2 $\Delta 7-8)$ has been reported in the general population, with the breakpoint described in intron $6[16,17]$. The frequency of this variant varies greatly among populations including $15-21 \%$ in non-Finish Europeans, $7-11.5 \%$ in Americans and Finnish European individuals and 0.3-3\% in Asian and African populations $[17,18]$. Several studies observed a strong inverse correlation between this partial deletion and SMN2_CN suggesting that the $S M N 1 / 2 \Delta 7-8$ variant is mainly derived from SMN2 deletion events [17,19].

Apart from partial deletions of $S M N$ genes, other structural variants have been characterized such as hybrid SMN1-SMN2 genes. Around 5-10\% of SMA patients show homozygous deletions of exon 7, but not of exon 8 of SMN1 explained by the presence of hybrid genes $[6,20,21]$. This phenomenon could result from intrachromosomal deletions or more likely from gene conversion events in which part of the SMN2 gene is fused to SMN1 [20,22]. Although there is still some debate, many studies found that hybrid SMN genes appeared to be associated with a milder phenotype, mainly present in SMA type II and III patients $[20,21,23]$.

Copy number of $S M N 1$ gene have also been described in the general population with differences across various ethnicities, with a higher average of SMN1 copies in African American population [24]. In fact, $54.7 \%$ of Africans carry three or more SMN1 copies according to a recent study [18]. In this context, the frequency of silent $2 / 0$ carriers (individuals with two SMN1 copies in cis) is also higher as it is directly related to the frequencies of SMN1 deletions and duplications [25,26]. The detection of $2 / 0$ carriers is challenging given the difficulty to differentiate them from $1 / 1$ non-carriers. Interestingly, two SMN1 variants have been associated with silent carriers in the Ashkenazi Jewish 
population, including c. ${ }^{*} 3+80 \mathrm{~T}>\mathrm{G}$ and c. ${ }^{*} 21{ }_{-}^{*} 212 \mathrm{del}$, which ultimately modify the SMA carrier risk being useful to detect around $20 \%$ of these special carriers [25,27]. However, it must be taken into account that there are several $2 / 0$ cases without these variants [27].

Therefore, an accurately deep characterization of the SMA region is relevant not only for the detection of SMN1 and SMN2 copy number, but also for the different structural variants described. There are complex biological features of the SMN region that hinder the analysis of these genes, including the high homology between both genes, the multiple SMN2 copies, the presence of partial deletions and hybrid structures and the effect of unknown intronic variants (Table 1). Technical limitations may include difficulties to ascribe a variant to $S M N 1$ or $S M N 2$, quantitation of SMN2 may not be always straightforward because of sample or methodological problems and structural changes are not usually detected with routine methods.

Table 1. Complex characteristics of $S M N$ genomic region and associated technical limitations. Left column shows the biological issues and the right column the technical difficulties associated with the analysis of all these complex issues.

\begin{tabular}{cc}
\hline Complex Biological Features of SMN Region & Technical Limitations \\
\hline High homology between SMN1 and SMN2 & $\begin{array}{c}\text { Difficulty in establishing if specific variants belong to SMN1 } \\
\text { or SMN2 } \\
\text { Multiple copies of SMN genes } \\
\text { Partial deletions }\end{array}$ \\
SMN2/SMN1 hybrid structures & $\begin{array}{c}\text { Inaccurate copy number determination } \\
\text { Unknown variants in deep intronic regions }\end{array}$ \\
\hline
\end{tabular}

\section{The Known Validated Genotypes}

Determination of SMN2_CN is a useful prognostic tool in order to establish accurate genotype-phenotype correlations, predict disease course and determine appropriate SMA patients for treatment [15]. Calucho et al. (2018) compiled a total of 3459 SMA patients and established quantitative SMN2 correlations to predict disease evolution. Concretely, the higher number of SMN2 copies, the milder the SMA phenotype, as most patients comply with the following rule: SMA type I patients had 2 SMN2 genes, type II had 3 SMN2, type III had 3 or 4 SMN2 copies and type IV patients had 4 SMN2 genes [15]. Later on, Ruhno et al. (2019) proposed a model to classify patients based on their SMN2 dosage, including concordant patients with an expected SMN2_CN for their disease severity, and discordant patients with either a milder or more severe phenotype. This model only differs from Calucho's correlations in type III patients, since it establishes the expected SMN2_CN to be 4 instead of 3 and 4 indistinctly [9]. In the recent literature, the correlation described by Calucho et al. (2018) is mainly maintained [28-32], although some exceptions can be found. Interestingly, the proportion of type I patients with 3 SMN2 genes was increased in some cohorts, reaching 57\% among SMA I patients, while Calucho's compilation reported only $23 \%$ [33,34]. In contrast, the cohort described by Sun et al. (2020) seems to have, in global numbers, a better-than-expected phenotype, as the majority of SMA type II patients presented $2 S M N 2$ genes, type III patients had 2 or 3 SMN2 copies and more than half of SMA type IV had only 3 SMN2 genes [35]. Despite these differences in the literature, all studies agree that the higher the SMN2_CN, the less severe the SMA phenotype. This widely described correlation is coherent, since the higher number of SMN2 copies, the higher amounts of SMN functional protein produced compensating the lack of SMN1 gene and explaining the better prognosis of the patients.

Nevertheless, this correlation is not absolute and some discordant cases based on this rule are found, which can be further subdivided in "better-than-expected" or "worsethan-expected" patients [15]. In some of these individuals, apart from the SMN2_CN, different variants have been reported to modify the SMA phenotype, which can help inform prognostic outcomes. Two positive modifiers in SMN2 gene have been described, both associated with a milder phenotype [36-38]. The first modifier described was the variant 
c.859G >C (p.Gly287Arg) located in exon 7 of SMN2. It creates a novel exonic splicing enhancer site (SF2/ASF motif) predicted by ESEfinder 3.0 [36]. Through SMN splicing assays, it has been demonstrated to significantly increase SMN2 exon 7 inclusion in vitro from $40-50 \%$ to $70 \%$ and subsequently the amount of full-length $S M N$ transcript $[36,37]$. There is an additive effect of this variant, as the greater number of SMN2 copies with c. $859 \mathrm{G}>\mathrm{C}$, the better the phenotype of the patient. In addition, it has been postulated that this allele has originated from a common ancestor by haplotype analysis [39]. The second variant classified as a positive modifier is the variant c.835-44A $>\mathrm{G}$, located in intron 6 , and it is one of the 16 PSVs described between SMN1 and SMN2 [10,40]. Wu et al. (2017) demonstrated that this transition decreases the affinity of the RNA-binding protein HuR, which acts as a splicing repressor, increasing in $\sim 20 \%$ the SMN2 exon 7 inclusion [38]. Despite the rare frequency of at least c.859G $>C$ variant $(0.8 \%, 11 / 1345)$ [41], a recent SMA practical guideline recommends the evaluation of both variants in discordant SMA patients presenting a better-than-expected phenotype [42].

Other known modifier variants that could explain discordant cases based on SMN2_CN include SMN1 intragenic variants. More than 80 pathogenic variants have been described in SMN1 gene in compound heterozygous individuals, mainly located in the Tudor and C-terminal domains [43]. In general terms, in the Tudor domain, missense mutations appear to be associated with a more severe SMA phenotype, whereas in the context of frameshift and nonsense variants may be more dependent on the SMN2 copies [44,45]. For instance, c.275G $>C$ (p.Trp92Ser) variant has been reported in severe SMA type I patients with 3 SMN2 copies and a reduced interaction with SMN target proteins has been shown using a protein binding assay [46-48]. On the other hand, mutations in the C-terminal domain appear mostly related to a worse-than-expected phenotype as is the case of the variant c.770_780dup (p.Leu261Alafs*5) [21,31,49]. In our experience, compound heterozygous patients with this pathogenic variant and the SMN1 deletion carrying only one SMN2 copy had congenital type 0 disease [50], whereas patients with two or three SMN2 copies had type I or II disease, respectively [21].

In addition, some missense variants in exon 1 of $S M N 1$ are associated with a milder phenotype [44]. Two recurrent variants are c.5C $>\mathrm{T}$ (p.Ala2Val) and c.5C $>\mathrm{G}$ (p.Ala2Gly), which are considered hypomorphic alleles identified in SMA type III patients [51,52]. In fact, it has been shown in a SMA mouse model that the change p.Ala2Gly does not produce total loss of protein function [53] and no significant decrease of full-length SMN1 transcripts [43]. All these cases highlight the relevance of (1) performing additional functional studies to further characterize SMN1 pathogenic variants, both including novel and previously described variants, and (2) further characterize the SMN2 copies in those patients to better explain their phenotypes.

\section{The Unknown or Yet Non-Validated Genotypes}

Aside from the previously described SMN2 modifiers (c.859G $>C$ and c.835-44A $>$ G), other variants in this gene have been proposed to modify the SMA phenotype, although functional studies to demonstrate an effect in the SMN protein have not been performed or more cases have not yet been reported [9,38,54]. For instance, variants c.835-1897C $>\mathrm{T}$ and c. $835-549 \mathrm{~A}>\mathrm{G}$ in intron 6 of SMN2 and variant c. ${ }^{*} 3+100 \mathrm{G}>\mathrm{A}$ in intron 7 , later classified as a PSV [10], have been associated with a better-than-expected phenotype (Figure 1) [9,38]. Furthermore, a recent study suggested that variants c. $81+45 \mathrm{C}>\mathrm{T}$ in intron 1 of $S M N 2$ and c.838_840del in exon 7 were related to a more severe SMA phenotype. This work also identified a novel variant (c.-14C $>\mathrm{T}$ ) in the promoter region of the SMN2 gene in an SMA type I patient with apparently four $S M N 2$ copies indicating a possible association with a worse-than-expected phenotype [54]. In addition, variants in the SMN1 promoter, which have been associated with non-functional SMN1 alleles, have also been reported, even though they are infrequent findings [45]. It is important to bear in mind that variants located in deep intronic regions would not be detected through MLPA or exome sequencing, highlighting the importance of recently developed strategies for the entire sequencing of 
SMN1 or SMN2 genes [10,18]. Another cause of discordance could be a clinical misclassification of the patient or an inaccurate SMN2_CN determination. On the one hand, the lack of clinical information or the modification of the patient's phenotype due to natural history or evolving trajectory because of current treatments could lead to reassign the SMA type, thus generating discordance with its SMN2_CN [8]. On the other hand, many factors can affect the determination of SMN2 dosage, giving an inaccurate result. Although MLPA is considered the gold standard technique to detect the number of SMN2 copies in SMA patients, real-time PCR (RT-PCR) and droplet digital PCR (ddPCR) are also commonly used. In MLPA and RT-PCR based on SYBR Green, DNA quality is crucial to achieve reliable results, and moreover, both methods can be affected by variants in the target region of primers or probes, leading to a misinterpretation of the SMN2_CN. In addition, control samples or references are needed in all the approaches since they are based on indirect quantification, and therefore the right choice of these controls is decisive to establish the correct SMN2_CN [42]. This fact is reflected in the work of Schorling et al. (2019), in which 20 SMA patients were retested for their SMN2 dosage using new DNA samples and $45 \%$ of the results were discrepant in comparison with the initial ones [55]. Retesting of cohorts with discrepancies (i.e., [33-35]) would be interesting to confirm if some of the results are due to problems with SMN2_CN determination or clinical misclassification of patients. In fact, a guideline is proposed to manage the discordant situations that are present in SMA patients [42].

There are also some other genetic factors to consider that remain undetectable with routine techniques. First, different SMN1-SMN2 hybrid structures have been described, but using the available MLPAs only those hybrids formed by exons 1 to 7 of SMN2 and exon 8 of SMN1 (more common) or vice versa are detectable (see Figure 2). Blasco-Pérez et al. (2021) described two SMA patients with hybrid structures consisting of the entire $S M N 2$ gene except for a region of intron 6, corresponding to SMN1 [10]. This hybrid is undetectable using MLPA as this technique has only specific probes of SMN1 and SMN2 in exons 7 and 8 based on the exonic PSVs. Similarly, other uncommon hybrids (such as those reported by Cusco et al. (2001) [20], Qu et al. (2016) [43], Kubo et al. (2015) [51] or Blasco-Pérez et al. (2021) [10]) or partial deletions of SMN2 copies, would be detectable by the complete sequencing of $S M N$ genes or by the study of PSVs of the region $[10,18]$. Second, besides the common polymorphic $S M N 1 / 2 \Delta 7-8$, other partial deletions have been described, some of which are difficult to elucidate if they are located in SMN1 or SMN2 genes, further contributing to the complexity of the analysis [18,56]. Third, it has been described that $S M N 2$ can be hypermethylated, resulting in a partial inactivation of the gene expression, which translates into a worse-than-expected phenotype according to the patient's SMN2_CN [57]. Lastly, variants in regulatory regions outside the gene could modify its expression, either increasing or decreasing the amount of SMN protein produced by each copy of SMN2 as occurs with the modifier variants described within the gene. In fact, several targets of transcriptional regulation in the SMN2 locus are under study [58,59]. 


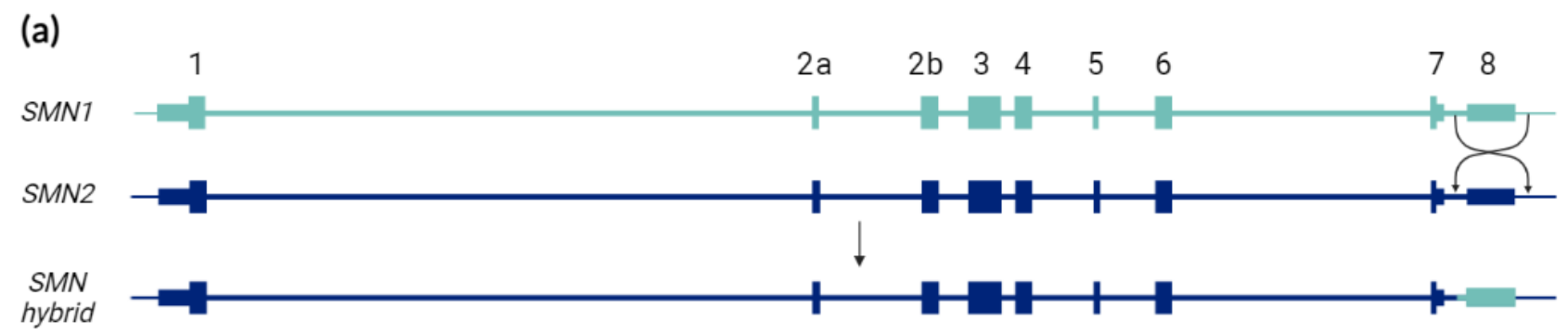

(b.1)

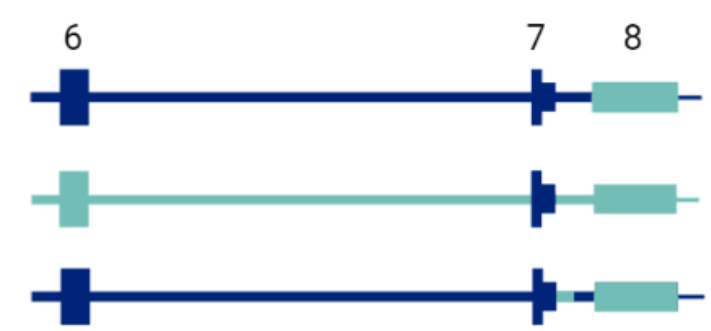

(b.2)

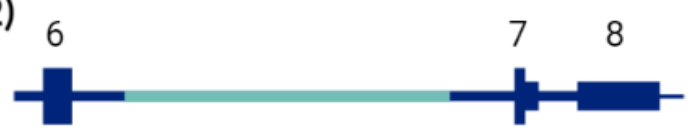

Figure 2. Schematic representation of different $S M N 2 / S M N 1$ hybrid structures reported in SMA patients. (a) Mechanism of formation of the classical SMN2/SMN1 hybrid structure detectable through MLPA and other routine techniques and usually defined as "homozygous deletion of only exon 7 of the SMN1 gene". (b.1) Previously reported SMN2/SMN1 hybrid structures indistinguishable from the classical one using MLPA and other routine techniques [20,43,51]. (b.2) Previously reported SMN2/SMN1 hybrid structure undetectable through MLPA and other routine techniques [10]. The hybrid structures from $(\mathbf{b})$ are detectable by sequencing of the entire SMN genes. The different PSV sequences in each structure may determine the expression and functionality of each of the hybrid genes. Light blue represents SMN1, and dark blue SMN2.

Several discordant haploidentical SMA siblings have been described, presenting the same number of SMN2 copies [60] and no differences by NGS analysis [9]. These cases are thought to be modulated by additional SMA genetic modifiers. Considering other possible SMA modifier genes, aside from SMN2, there are two candidates within the $5 q 13$ region, NAIP (neuronal apoptosis inhibitory protein) and SERF1A (small EDRK-rich factor 1a). These genes have been found to be deleted in a proportion of patients, particularly with a more severe phenotype. However, results are inconclusive and it is more likely to be caused by a contiguity effect of the $S M N$ deletion [61,62]. In addition, other factors outside the SMN gene locus may be involved in the SMN2 response-activity and in the SMA phenotype's definition. These factors are usually divided into $S M N$-dependent factors, which directly alter the amount of SMN protein, and $S M N$-independent factors playing a role in many different functions such as actin polymerization, cytoskeleton dynamics or neurogenesis [63]. For instance, PLS3 (plastin 3) gene has been proposed to possibly modulate SMA disease progression in discordant SMA siblings as higher expression levels were found in lymphoblasts in sisters with milder phenotypes [64]. However, up to date, no DNA markers or modifiers that lie outside the SMA region have been validated in clinical settings [9]. Nevertheless, a thorough discussion of these modifiers can be found elsewhere [63,65]. A representative list of possible modifiers of SMA phenotype and their references is summarized in Table 2. 
Table 2. Possible modifiers of spinal muscular atrophy. This is a representative list to show the different lines of investigation to determine factors that may modify the SMN function and SMA phenotype. Even though we include several factors, the SMN2 gene (copy number, sequence and structure) is the only validated as a DNA marker. Based on references [15,63-75]. Arrow indicates increase (up) or decrease (down).

\begin{tabular}{cccc}
\hline Modifier Type & Example & Effect & Reference \\
\hline SMA locus & SMN2 copies and variants & SMA types & Calucho et al. 2018 [15] \\
Splicing regulators & hnRNP-A1/Sam68 & Exon 7 inclusion & Pedrotti et al. 2010 [66] \\
SMN degradation & UBA1 & $\uparrow$ Survival SMA mice & Powis et al. 2016 [67] \\
DNA methylation & SLC23A2/NCOR2 & SMA types differences & Zheleznyakova et al. 2015 [68] \\
Actin polymerization & PS3 & Siblings differences & Oprea et al. 2008 [64] \\
Cytoskeleton dynamics & ERK & $\uparrow$ Survival SMA mice & Branchu et al. 2013 [69] \\
Endocytosis regulators & NCALD & Ameliorates SMA & Riessland et al. 2017 [70] \\
Neurogenesis regulators & PTEN & $\uparrow$ Survival SMA mice & Little et al. 2015 [71] \\
Axogenesis & ZPR1 & $\downarrow$ in SMA patients & Helmken et al. 2003 [72] \\
Apoptosis & Bcl2 & $\downarrow$ SMA motor neurons & Soler-Botija et al. 2003 [73] \\
Hormones/growth factors & Prolactin & $\uparrow$ Survival SMA mice & Farooq et al. 2011 [74] \\
Environmental factors & Exercise & $\uparrow$ Survival SMA mice & Grondard et al. 2005 [75] \\
\hline
\end{tabular}

\section{Evolving Therapies and the Importance of SMN2}

In the SMA therapeutic background, there are three approved therapies by the FDA (Food and Drug Administration) and EMA (European Medicines Agency): nusinersen, risdiplam and onasemnogene abeparvovec-xioi (OA). Nusinersen and risdiplam agents are designed to bind specifically to $S M N 2$ pre-mRNA in order to promote exon 7 inclusion increasing the amount of functional SMN protein $[76,77]$. The remainder approved SMA treatment $\mathrm{OA}$, consists of a gene replacement therapy that restores the expression of normal SMN1 using a viral vector (AAV9) expressing SMN1 [78]. While the SMN2 endogenous target regions comprise splicing regulators and intronic regions, the SMN1 transgene in the AAV9 is an SMN1 cDNA lacking intronic or other regulatory elements. At first sight, the identification of SMN2 copies, variants and structures would be of particular interest for the approved SMA treatments targeting SMN2. However, this information could be also useful for patients treated with OA. Indeed, the c. $859 \mathrm{G}>\mathrm{C}$ variant was relevant in the AVXS101 trial as it was defined as an exclusion criteria, albeit the approval was given without limitation on the genetic background [78]. For example, in the context of presymptomatic detection, a neonate with 2 copies of $S M N 2$ carrying the c.859G $>C$ variant will have a better evolution than typical cases with 2 SMN2 copies without this modifier variant [39]. In view of the current progress in the worldwide implementation of neonatal screening, when a neonate is genetically diagnosed with SMA, it is recommended to perform not only SMN2_CN determination, but also a more complete SMN2 characterization, including variants and if possible, structural changes [42]. While the influence of $S M N$ hybrid genes and partial deletions on the response of the different therapies has not yet been addressed, it can be speculated that therapeutic efficacy of $S M N 2$ modulators may be affected depending on particular hybrid structures [10]. The NGS approach of the complete SMN2 genes is also useful to determine regions of the SMN2 that are apparently highly conserved within the patients. For example, the ISSN1 sequence of intron 7, an interesting region because it is the target of the 18bp oligonucleotide nusinersen, appears to be so far identical in SMA patients [10], but further studies with a larger number of cases should be performed to confirm this observation.

Upon approvals, the availability of different therapies is complicating the decisionmaking for treatment choices. Besides monotherapy, several SMA patients are receiving combinatorial therapies starting with nusinersen and after OA or vice versa [79-81], and combination could also include risdiplam (individual reports). In principle, the mechanisms of action of these therapies do not interfere specifically with each other but are rather complementary. For example, any patient receiving gene therapy, will produce SMN protein autonomously and theoretically indefinitely as an episome in the nucleus 
of postmitotic cells and the endogenous SMN2 could still be a possible target for SMN2 modulators. However, the regulation and feedback that modulate SMN production by both mechanisms have not been elucidated yet. Recently, it has been reported that the overexpression of SMN protein by AAV9 has long-term neuronal toxic effects in a SMA mouse model [82]. Therefore, the putative overproduction of SMN with combinatorial therapies should also be cautiously considered in SMA patients, particularly in those who already received gene therapy. A recent consensus statement on gene replacement therapy for SMA does not recommend combinatorial therapy as part of routine care [83]. Further studies should be performed to determine when combinatorial therapies would be more effective than monotherapy. In the current scenario, combinatorial therapies may also include SMN-independent compounds, which are worth to be further investigated in SMA patients [84]. Interestingly, a recent study has showed promising results with the combinatorial use of an antisense oligonucleotide (ASO) mimicking nusinersen and an orally delivered histone deacetylase inhibitor (panobinostat) in SMA cell models. They have found that this compound increases the effects of the ASO on SMN2 exon 7 inclusion enhancing the expression of SMN2 [85]. As this is a constantly evolving field, regardless of the treatment received, all SMA cases may benefit from knowing their complete SMN2 genotype to make better and tight correlations with each phenotype and more realistic outcomes after therapies.

\section{Conclusions}

The present therapeutic scenario highlights the importance to genetically confirm SMA patients in order to make them eligible for treatment options. Although the vast majority of patients can be straightforwardly diagnosed, it is important to be aware of rare particular SMN1 deletions or variants that may be critical to genetically confirm a given patient [56]. Once bi-allelic SMN1 alterations are confirmed, SMN2 enters the scene for better prognostic and phenotype characterizations. Discordant situations of genotype-phenotype correlation in SMA exist including when a phenotype of a given patient is better-thanexpected according to SMN2 copies (fewer copies, better phenotype) or conversely, when the phenotype is worse-than-expected according to SMN2 copies (more copies, but more severe phenotype). These discordances may be due to biological or technical issues and all discordant cases should be retested considering a new sample, a different methodology and/or even another laboratory (Figure 3). Testing for positive known variants that may influence the amount of complete SMN should be performed once the copy number results are confirmed. NGS studies of the entire gene allow further characterization of the quality of SMN2 copies. Better-than-expected discordances are usually explained by known positive variants in SMN2, but some cases still remain unexplained and further genetic investigations may unravel potential causes that explain the phenotype. In our experience, worse-than-expected cases are usually due to technical pitfalls (SMN2_CN overestimation), although negative modifiers are under validation studies. Partial deletions of SMN2 may be masked if SMN2 sequencing or quantitation is not carefully evaluated. Copy number results may be complemented with NGS of the entire SMN2 genes to define their sequence and structure and detect further modifiers. Confirmation of copy number can also be achieved with NGS studies [10]. Finally, the therapeutic context of SMA is becoming more complex and expanded with several SMN-dependent or SMN-independent therapeutic approaches. Thus, combinatorial therapies are expected to be protocolized in the future, when more evidence about their efficacy is available [84]. All these advances should consider SMN2 copies, variants and structures as part of the integral characterization of patients receiving expensive and sometimes lifelong therapies. The SMN2 gene, as the main modifier of SMA phenotype, warrants a deeper study beyond the copy number determination. In the near future, either in the presymptomatic neonatal screening scenario or in already symptomatic patients, routine analysis may be adapted to currently detect rare (modifier) variants, single-nucleotide polymorphisms and structural variants of the SMN locus. 


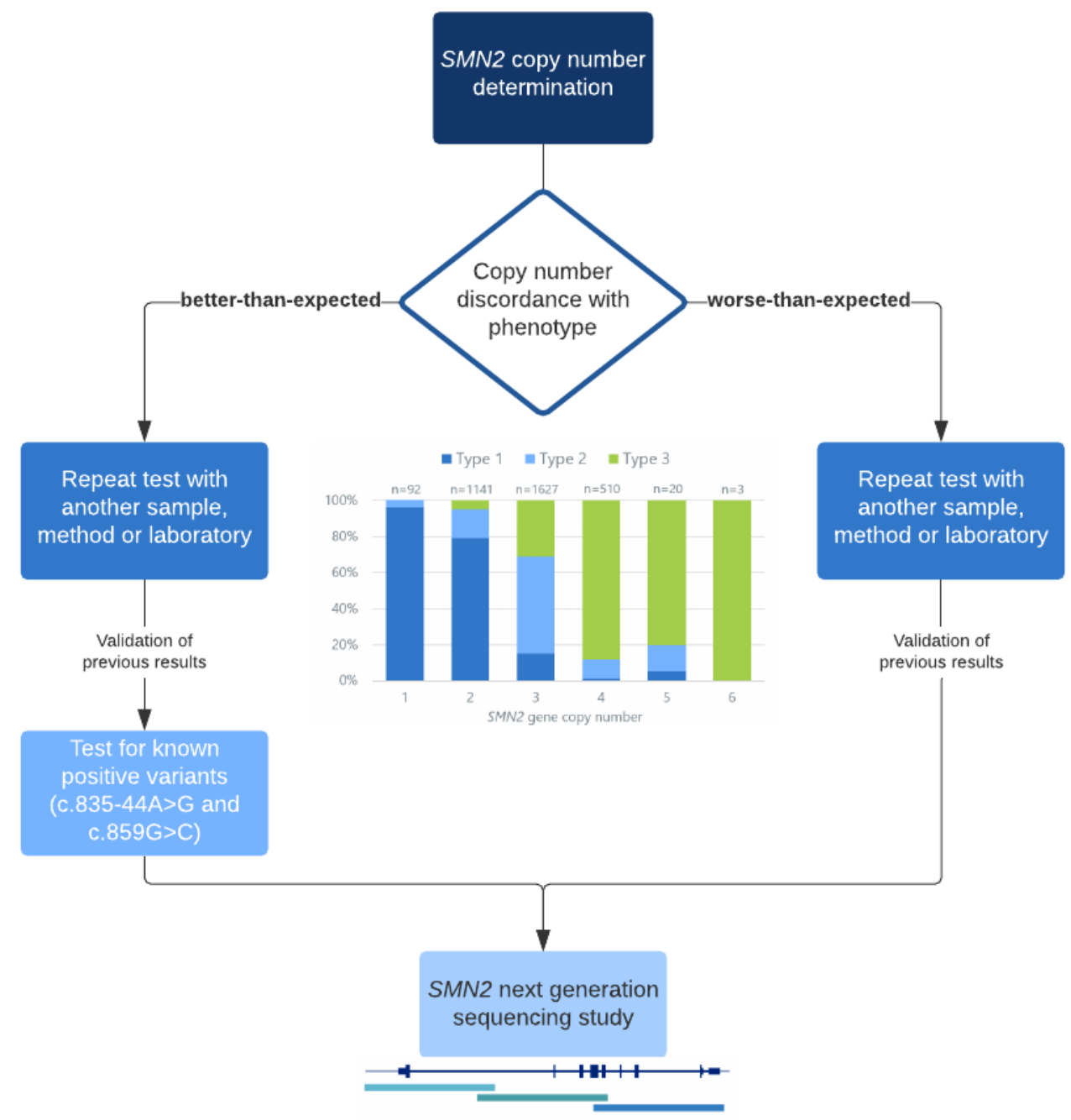

Figure 3. Workflow for discordant SMA symptomatic patients. Once SMN2 is determined and discordance is found (according to the graphic in the center of the workflow based on the metaanalysis of 3459 cases from Calucho et al. (2018) [15]), a re-test should be performed with a new sample, another method or even another laboratory. If the discrepancy is confirmed, when the phenotype is better than expected, we may test for known and validated positive variants (c.859G>C and c.835-44A $>$ G). If negative, we may continue with further NGS studies (as in [10]). In case that the phenotype is worse than expected, we should perform an NGS test in order to determine potential negative modifiers, hybrid structures or intragenic deletions that may explain the phenotype. Based on reference [42].

Author Contributions: M.C.-R.; L.B.-P. writing-original draft preparation and data curation. I.C., E.F.T. Conceptualization, writing review and editing. All authors have read and agreed to the published version of the manuscript.

Funding: This work was partially supported by Grants from Biogen and Roche (to E.F.T. supporting M.C.-R. and L.B.-P.), and from Spanish Instituto de Salud Carlos III, Fondo de Investigaciones Sanitarias and cofunded with ERDF funds (Grant No. FIS PI18/000687) (to E.F.T.).

Institutional Review Board Statement: Not applicable.

Informed Consent Statement: Not applicable.

Data Availability Statement: Not applicable 
Conflicts of Interest: E.F.T. discloses grant support to conduct CTs on SMA from Ionis/Biogen and serves as a consultant to AveXis, Novartis, Biogen, Biologix, Cytokinetics, and Roche. The other authors report no disclosures relevant to the manuscript.

\section{References}

1. Kolb, S.J.; Kissel, J.T. Spinal Muscular Atrophy. Neurol. Clin. 2015, 33, 831-846. [CrossRef]

2. Sugarman, E.; Nagan, N.; Zhu, H.; Akmaev, V.; Zhou, Z.; Rohlfs, E.; Flynn, K.; Hendrickson, B.; Scholl, T.; Sirko-Osadsa, D.; et al. Pan-ethnic carrier screening and prenatal diagnosis for spinal muscular atrophy: Clinical laboratory analysis of $>72,400$ specimens. Eur. J. Hum. Genet. 2012, 20, 27-32. [CrossRef]

3. Prior, T.W.; Leach, M.E.; Finanger, E. Spinal Muscular Atrophy. In GeneReviews ${ }^{\circledR}$; Adam, M.P., Ardinger, H.H., Pagon, R.A., Wallace, S.E., Bean, L.J.H., Mirzaa, G., Amemiya, A., Eds.; University of Washington: Seattle, WA, USA, 2000; updated 3 December 2020; Available online: Website (accessed on 28 July 2021).

4. Talbot, K.; Tizzano, E.F. The clinical landscape for SMA in a new therapeutic era. Gene Ther. 2017, 24, 529-533. [CrossRef]

5. Lefebvre, S.; Bürglen, L.; Reboullet, S.; Clermont, O.; Burlet, P.; Viollet, L.; Benichou, B.; Cruaud, C.; Millasseau, P.; Zeviani, M.; et al. Identification and characterization of a spinal muscular atrophy-determining gene. Cell 1995, 80, 155-165. [CrossRef]

6. Wirth, B. An update of the mutation spectrum of the survival motor neuron gene (SMN1) in autosomal recessive spinal muscular atrophy (SMA). Hum. Mutat. 2000, 15, 228-237. [CrossRef]

7. Bürglen, L.; Lefebvre, S.; Clermont, O.; Burlet, P.; Viollet, L.; Cruaud, C.; Munnich, A.; Melki, J. Structure and organization of the human survival motor neurone (SMN) gene. Genomics 1996, 32, 479-482. [CrossRef]

8. Rochette, C.; Gilbert, N.; Simard, L. SMN gene duplication and the emergence of the SMN2 gene occurred in distinct hominids: SMN2 is unique to Homo sapiens. Hum. Genet. 2001, 108, 255-266. [CrossRef] [PubMed]

9. Ruhno, C.; McGovern, V.L.; Avenarius, M.R.; Snyder, P.J.; Prior, T.W.; Nery, F.C.; Muhtaseb, A.; Roggenbuck, J.S.; Kissel, J.T.; Sansone, V.A.; et al. Complete sequencing of the SMN2 gene in SMA patients detects SMN gene deletion junctions and variants in SMN2 that modify the SMA phenotype. Hum. Genet. 2019, 138, 241-256. [CrossRef] [PubMed]

10. Blasco-Pérez, L.; Paramonov, I.; Leno, J.; Bernal, S.; Alias, L.; Fuentes-Prior, P.; Cuscó, I.; Tizzano, E.F. Beyond copy number: A new, rapid, and versatile method for sequencing the entire SMN2 gene in SMA patients. Hum. Mutat. 2021, 42, 787-795. [CrossRef]

11. Lorson, C.L.; Hahnen, E.; Androphy, E.J.; Wirth, B. A single nucleotide in the SMN gene regulates splicing and is responsible for spinal muscular atrophy. Proc. Natl. Acad. Sci. USA 1999, 96, 6307-6311. [CrossRef] [PubMed]

12. Soler-Botija, C.; Cuscó, I.; Caselles, L.; López, E.; Baiget, M.; Tizzano, E.F. Implication of fetal SMN2 expression in type I SMA pathogenesis: Protection or pathological gain of function? J. Neuropathol. Exp. Neurol. 2005, 64, 215-223. [CrossRef]

13. Wirth, B.; Garbes, L.; Riessland, M. How genetic modifiers influence the phenotype of spinal muscular atrophy and suggest future therapeutic approaches. Curr. Opin. Genet. Dev. 2013, 23, 330-338. [CrossRef]

14. Boza-Morán, M.G.; Martínez-Hernández, R.; Bernal, S.; Wanisch, K.; Also-Rallo, E.; Le Heron, A.; Alías, L.; Denis, C.; Girard, M.; Yee, J.; et al. Decay in survival motor neuron and plastin 3 levels during differentiation of iPSC-derived human motor neurons. Sci. Rep. 2015, 5, 11696. [CrossRef] [PubMed]

15. Calucho, M.; Bernal, S.; Alías, L.; March, F.; Venceslá, A.; Rodríguez-Álvarez, F.J.; Aller, E.; Fernández, R.M.; Borrego, S.; Millán, J.M.; et al. Correlation between SMA type and SMN2 copy number revisited: An analysis of 625 unrelated Spanish patients and a compilation of 2834 reported cases. Neuromuscul. Disord. 2018, 28, 208-215. [CrossRef] [PubMed]

16. Arkblad, E.L.; Darin, N.; Berg, K.; Kimber, E.; Brandberg, G.; Lindberg, C.; Holmberg, E.; Tulinius, M.; Nordling, M. Multiplex ligation-dependent probe amplification improves diagnostics in spinal muscular atrophy. Neuromuscul. Disord. 2006, 16, 830-838. [CrossRef] [PubMed]

17. Vijzelaar, R.; Snetselaar, R.; Clausen, M.; Mason, A.G.; Rinsma, M.; Zegers, M.; Molleman, N.; Boschloo, R.; Yilmaz, R.; Kuilboer, R.; et al. The frequency of SMN gene variants lacking exon 7 and 8 is highly population dependent. PLoS ONE 2019, 14, e0220211. [CrossRef]

18. Chen, X.; Sanchis-Juan, A.; French, C.E.; Connell, A.J.; Delon, I.; Kingsbury, Z.; Chawla, A.; Halpern, A.L.; Taft, R.J.; Bentley, D.R.; et al. Spinal muscular atrophy diagnosis and carrier screening from genome sequencing data. Genet. Med. 2020, 22, 945-953. [CrossRef]

19. Alías, L.; Bernal, S.; Barceló, M.J.; Also-Rallo, E.; Martínez-Hernández, R.; Rodríguez-Alvarez, F.J.; Hernández-Chico, C.; Baiget, M.; Tizzano, E.F. Accuracy of marker analysis, quantitative real-time polymerase chain reaction, and multiple ligation-dependent probe amplification to determine SMN2 copy number in patients with spinal muscular atrophy. Genet. Test. Mol. Biomark. 2011, 15, 587-594. [CrossRef] [PubMed]

20. Cuscó, I.; Barceló, M.J.; del Rio, E.; Martín, Y.; Hernández-Chico, C.; Bussaglia, E.; Baiget, M.; Tizzano, E.F. Characterisation of SMN hybrid genes in Spanish SMA patients: De novo, homozygous and compound heterozygous cases. Hum. Genet. 2001, 108, 222-229. [CrossRef]

21. Alías, L.; Bernal, S.; Fuentes-Prior, P.; Barceló, M.J.; Also, E.; Martínez-Hernández, R.; Rodríguez-Alvarez, F.J.; Martín, Y.; Aller, E.; Grau, E.; et al. Mutation update of spinal muscular atrophy in Spain: Molecular characterization of 745 unrelated patients and identification of four novel mutations in the SMN1 gene. Hum. Genet. 2009, 125, 29-39. [CrossRef] 
22. Hahnen, E.; Schönling, J.; Rudnik-Schöneborn, S.; Zerres, K.; Wirth, B. Hybrid survival motor neuron genes in patients with autosomal recessive spinal muscular atrophy: New insights into molecular mechanisms responsible for the disease. Am. J. Hum. Genet. 1996, 59, 1057-1065. [PubMed]

23. Niba, E.T.E.; Nishio, H.; Wijaya, Y.O.S.; Lai, P.S.; Tozawa, T.; Chiyonobu, T.; Yamadera, M.; Okamoto, K.; Awano, H.; Takeshima, Y.; et al. Clinical phenotypes of spinal muscular atrophy patients with hybrid SMN gene. Brain Dev. 2021, 43, 294-302. [CrossRef] [PubMed]

24. Hendrickson, B.; Donohoe, C.; Akmaev, V.; Sugarman, E.; Labrousse, P.; Boguslavskiy, L.; Flynn, K.; Rohlfs, E.; Walker, A.; Allitto, B.; et al. Differences in SMN1 allele frequencies among ethnic groups within North America. J. Med. Genet. 2009, 46, 641-644. [CrossRef] [PubMed]

25. Luo, M.; Liu, L.; Peter, I.; Zhu, J.; Scott, S.A.; Zhao, G.; Eversley, C.; Kornreich, R.; Desnick, R.J.; Edelmann, L. An Ashkenazi Jewish SMN1 haplotype specific to duplication alleles improves pan-ethnic carrier screening for spinal muscular atrophy. Genet. Med. 2014, 16, 149-156. [CrossRef]

26. Alías, L.; Barceló, M.J.; Bernal, S.; Martínez-Hernández, R.; Also-Rallo, E.; Vázquez, C.; Santana, A.; Millán, J.M.; Baiget, M.; Tizzano, E.F. Improving detection and genetic counseling in carriers of spinal muscular atrophy with two copies of the SMN1 gene. Clin. Genet. 2014, 85, 470-475. [CrossRef]

27. Alías, L.; Bernal, S.; Calucho, M.; Martínez, E.; March, F.; Gallano, P.; Fuentes-Prior, P.; Abuli, A.; Serra-Juhe, C.; Tizzano, E.F. Utility of two SMN1 variants to improve spinal muscular atrophy carrier diagnosis and genetic counselling. Eur. J. Hum. Genet. 2018, 26, 1554-1557. [CrossRef]

28. Coratti, G.; Messina, S.; Lucibello, S.; Pera, M.C.; Montes, J.; Pasternak, A.; Bovis, F.; Escudero, J.E.; Mazzone, E.S.; Mayhew, A.; et al. Clinical Variability in Spinal Muscular Atrophy Type III. Ann. Neurol. 2020, 88, 1109-1117. [CrossRef]

29. Osredkar, D.; Jílková, M.; Butenko, T.; Loboda, T.; Golli, T.; Fuchsová, P.; Rohlenová, M.; Haberlova, J. Children and young adults with spinal muscular atrophy treated with nusinersen. Eur. J. Paediatr. Neurol. 2021, 30, 1-8. [CrossRef]

30. Ou, S.; Ho, C.; Lee, W.; Lin, K.; Jones, C.; Jong, Y. Natural history in spinal muscular atrophy Type I in Taiwanese population: A longitudinal study. Brain Dev. 2021, 43, 127-134. [CrossRef] [PubMed]

31. Souza, P.; Pinto, W.; Ricarte, A.; Badia, B.; Seneor, D.; Teixeira, D.; Caetano, L.; Gonçalves, E.; Chieia, M.; Farias, I.; et al. Clinical and radiological profile of patients with spinal muscular atrophy type 4. Eur. J. Neurol. 2021, 28, 609-619. [CrossRef]

32. Zhang, Y.; He, J.; Zhang, Y.; Li, L.; Tang, X.; Wang, L.; Guo, J.; Jin, C.; Tighe, S.; Zhang, Y.; et al. The analysis of the association between the copy numbers of survival motor neuron gene 2 and neuronal apoptosis inhibitory protein genes and the clinical phenotypes in 40 patients with spinal muscular atrophy: Observational study. Medicine (Baltim.) 2020, 99, e18809. [CrossRef] [PubMed]

33. Lusakowska, A.; Jedrzejowska, M.; Kaminska, A.; Janiszewska, K.; Grochowski, P.; Zimowski, J.; Sierdzinski, J.; KosteraPruszczyk, A. Observation of the natural course of type 3 spinal muscular atrophy: Data from the polish registry of spinal muscular atrophy. Orphanet J. Rare Dis. 2021, 16. [CrossRef] [PubMed]

34. Aragon-Gawinska, K.; Seferian, A.; Daron, A.; Gargaun, E.; Vuillerot, C.; Cances, C.; Ropars, J.; Chouchane, M.; Cuppen, I.; Hughes, I.; et al. Nusinersen in patients older than 7 months with spinal muscular atrophy type 1: A cohort study. Neurology 2018, 91, e1312-e1318. [CrossRef] [PubMed]

35. Sun, Y.; Kong, X.; Zhao, Z.; Zhao, X. Mutation analysis of 419 family and prenatal diagnosis of 339 cases of spinal muscular atrophy in China. BMC Med. Genet. 2020, 21, 133. [CrossRef]

36. Prior, T.W.; Krainer, A.R.; Hua, Y.; Swoboda, K.J.; Snyder, P.C.; Bridgeman, S.J.; Burghes, A.H.M.; Kissel, J.T. A Positive Modifier of Spinal Muscular Atrophy in the SMN2 Gene. Am. J. Hum. Genet. 2009, 85, 408-413. [CrossRef]

37. Vezain, M.; Saugier-Veber, P.; Goina, E.; Touraine, R.; Manel, V.; Toutain, A.; Fehrenbach, S.; Frébourg, T.; Pagani, F.; Tosi, M.; et al. A rare SMN2 variant in a previously unrecognized composite splicing regulatory element induces exon 7 inclusion and reduces the clinical severity of spinal muscular atrophy. Hum. Mutat. 2010, 31, E1110-E1125. [CrossRef]

38. Wu, X.; Wang, S.H.; Sun, J.; Krainer, A.R.; Hua, Y.; Prior, T.W. A-44G transition in SMN2 intron 6 protects patients with spinal muscular atrophy. Hum. Mol. Genet. 2017, 26, 2768-2780. [CrossRef]

39. Bernal, S.; Alías, L.; Barceló, M.J.; Also-Rallo, E.; Martínez-Hernández, R.; Gámez, J.; Guillén-Navarro, E.; Rosell, J.; Hernando, I.; Rodríguez-Alvarez, F.J.; et al. The c.859G>C variant in the SMN2 gene is associated with types II and III SMA and originates from a common ancestor. J. Med. Genet. 2010, 47, 640-642. [CrossRef]

40. Monani, U.R.; Lorson, C.L.; Parsons, D.W.; Prior, T.W.; Androphy, E.J.; Burghes, A.H.M.; McPherson, J.D. A single nucleotide difference that alters splicing patterns distinguishes the SMA gene SMN1 from the copy gene SMN2. Hum. Mol. Genet. 1999, 8, 1177-1183. [CrossRef]

41. Bowen, B.M.; Truty, R.; Aradhya, S.; Bristow, S.L.; Johnson, B.A.; Morales, A.; Tan, C.A.; Westbrook, M.J.; Winder, T.L.; Chavez, J.C. SMA Identified: Clinical and Molecular Findings From a Sponsored Testing Program for Spinal Muscular Atrophy in More Than 2,000 Individuals. Front. Neurol. 2021, 12, 676. [CrossRef]

42. Cuscó, I.; Bernal, S.; Blasco-Pérez, L.; Calucho, M.; Alias, L.; Fuentes-Prior, P.; Tizzano, E.F. Practical guidelines to manage discordant situations of SMN2 copy number in patients with spinal muscular atrophy. Neurol. Genet. 2020, 6, e530. [CrossRef] [PubMed] 
43. Qu, Y.; Bai, J.; Cao, Y.; Wang, H.; Jin, Y.; Du, J.; Ge, X.; Zhang, W.; Li, Y.; He, S.; et al. Mutation Spectrum of the Survival of Motor Neuron 1 and Functional Analysis of Variants in Chinese Spinal Muscular Atrophy. J. Mol. Diagn. 2016, 18, 741-752. [CrossRef] [PubMed]

44. Wijaya, Y.; Ar Rohmah, M.; Niba, E.; Morisada, N.; Noguchi, Y.; Saito, K.; Nishio, H.; Shinohara, M. Phenotypes of SMA patients retaining SMN1 with intragenic mutation. Brain Dev. 2021, 43, 745-758. [CrossRef] [PubMed]

45. Cuscó, I.; Barceló, M.; del Río, E.; Baiget, M.; Tizzano, E. Detection of novel mutations in the SMN Tudor domain in type I SMA patients. Neurology 2004, 63, 146-149. [CrossRef] [PubMed]

46. Kotani, T.; Sutomo, R.; Sasongko, T.; Sadewa, A.; Gunadi; Minato, T.; Fujii, E.; Endo, S.; Lee, M.; Ayaki, E.; et al. A novel mutation at the N-terminal of SMN Tudor domain inhibits its interaction with target proteins. J. Neurol. 2007, 254, 624-630. [CrossRef]

47. Yamamoto, T.; Sato, H.; Lai, P.S.; Nurputra, D.K.; Harahap, N.I.F.; Morikawa, S.; Nishimura, N.; Kurashige, T.; Ohshita, T.; Nakajima, H.; et al. Intragenic mutations in SMN1 may contribute more significantly to clinical severity than SMN2 copy numbers in some spinal muscular atrophy (SMA) patients. Brain Dev. 2014, 36, 914-920. [CrossRef]

48. Takarada, T.; Rochmah, M.A.; Harahap, N.; Shinohara, M.; Saito, T.; Saito, K.; Lai, P.; Bouike, Y.; Takeshima, Y.; Awano, H.; et al. SMA mutations in SMN Tudor and C-terminal domains destabilize the protein. Brain Dev. 2017, 39, 606-612. [CrossRef]

49. Parsons, D.; McAndrew, P.; Monani, U.; Mendell, J.; Burghes, A.; Prior, T. An 11 base pair duplication in exon 6 of the SMN gene produces a type I spinal muscular atrophy (SMA) phenotype: Further evidence for SMN as the primary SMA-determining gene. Hum. Mol. Genet. 1996, 5, 1727-1732. [CrossRef]

50. Mendonça, R.; Rocha, A.; Lozano-Arango, A.; Diaz, A.; Castiglioni, C.; Silva, A.; Reed, U.; Kulikowski, L.; Paramonov, I.; Cuscó, I.; et al. Severe brain involvement in 5q spinal muscular atrophy type 0. Ann. Neurol. 2019, 86, 458-462. [CrossRef]

51. Kubo, Y.; Nishio, H.; Saito, K. A new method for SMN1 and hybrid SMN gene analysis in spinal muscular atrophy using long-range PCR followed by sequencing. J. Hum. Genet. 2015, 60, 233-239. [CrossRef]

52. Mendonça, R.; Matsui, C.; Polido, G.; Silva, A.; Kulikowski, L.; Dias, A.T.; Zanardo, E.; Solla, D.; Kok, F.; Reed, U.; et al. Intragenic variants in the SMN1 gene determine the clinical phenotype in 5q spinal muscular atrophy. Neurol. Genet. 2020, 6, e505. [CrossRef] [PubMed]

53. Monani, U.R.; Pastore, M.T.; Gavrilina, T.O.; Jablonka, S.; Le, T.T.; Andreassi, C.; DiCocco, J.M.; Lorson, C.; Androphy, E.J.; Sendtner, M.; et al. A transgene carrying an A2G missense mutation in the SMN gene modulates phenotypic severity in mice with severe (type I) spinal muscular atrophy. J. Cell Biol. 2003, 160, 41-52. [CrossRef]

54. Wadman, R.I.; Jansen, M.D.; Stam, M.; Wijngaarde, C.A.; Curial, C.A.D.; Medic, J.; Sodaar, P.; Schouten, J.; Vijzelaar, R.; Lemmink, H.H.; et al. Intragenic and structural variation in the SMN locus and clinical variability in spinal muscular atrophy. Brain Commun. 2020, 2, 1-13. [CrossRef] [PubMed]

55. Schorling, D.; Becker, J.; Pechmann, A.; Langer, T.; Wirth, B.; Kirschner, J. Discrepancy in redetermination of SMN2 copy numbers in children with SMA. Neurology 2019, 93, 267-269. [CrossRef] [PubMed]

56. Jedličková, I.; Přistoupilová, A.; Nosková, L.; Majer, F.; Stránecký, V.; Hartmannová, H.; Hodaňová, K.; Trešlová, H.; Hýblová, M.; Solár, P.; et al. Spinal muscular atrophy caused by a novel Alu-mediated deletion of exons 2a-5 in SMN1 undetectable with routine genetic testing. Mol. Genet. Genom. Med. 2020, 8, 1-10. [CrossRef] [PubMed]

57. Hauke, J.; Riessland, M.; Lunke, S.; Eyüpoglu, I.; Blümcke, I.; El-Osta, A.; Wirth, B.; Hahnen, E. Survival motor neuron gene 2 silencing by DNA methylation correlates with spinal muscular atrophy disease severity and can be bypassed by histone deacetylase inhibition. Hum. Mol. Genet. 2009, 18, 304-317. [CrossRef]

58. Woo, C.J.; Maier, V.K.; Davey, R.; Brennan, J.; Li, G.; Brothers, J.; Schwartz, B.; Gordo, S.; Kasper, A.; Okamoto, T.R.; et al. Gene activation of SMN by selective disruption of lncRNA-mediated recruitment of PRC2 for the treatment of spinal muscular atrophy. Proc. Natl. Acad. Sci. USA 2017, 114, E1509-E1518. [CrossRef] [PubMed]

59. Nizzardo, M.; Simone, C.; Dametti, S.; Salani, S.; Ulzi, G.; Pagliarani, S.; Rizzo, F.; Frattini, E.; Pagani, F.; Bresolin, N.; et al. Spinal muscular atrophy phenotype is ameliorated in human motor neurons by SMN increase via different novel RNA therapeutic approaches. Sci. Rep. 2015, 5, 1-13. [CrossRef]

60. Cuscó, I.; Barceló, M.; Rojas-García, R.; Illa, I.; Gámez, J.; Cervera, C.; Pou, A.; Izquierdo, G.; Baiget, M.; Tizzano, E. SMN2 copy number predicts acute or chronic spinal muscular atrophy but does not account for intrafamilial variability in siblings. J. Neurol. 2006, 253, 21-25. [CrossRef]

61. Medrano, S.; Monges, S.; Gravina, L.P.; Alías, L.; Mozzoni, J.; Aráoz, H.V.; Bernal, S.; Moresco, A.; Chertkoff, L.; Tizzano, E. Genotype-phenotype correlation of SMN locus genes in spinal muscular atrophy children from Argentina. Eur. J. Paediatr. Neurol. 2016, 20, 910-917. [CrossRef]

62. Brkušanin, M.; Kosać, A.; Jovanović, V.; Pešović, J.; Brajušković, G.; Dimitrijević, N.; Todorović, S.; Romac, S.; Rašić, V.M.; Savić-Pavićević, D. Joint effect of the SMN2 and SERF1A genes on childhood-onset types of spinal muscular atrophy in Serbian patients. J. Hum. Genet. 2015, 60, 723-728. [CrossRef]

63. Wirth, B. Spinal Muscular Atrophy: In the Challenge Lies a Solution. Trends Neurosci. 2021, 44, 306-322. [CrossRef]

64. Oprea, G.; Kröber, S.; McWhorter, M.; Rossoll, W.; Müller, S.; Krawczak, M.; Bassell, G.; Beattie, C.; Wirth, B. Plastin 3 is a protective modifier of autosomal recessive spinal muscular atrophy. Science 2008, 320, 524-527. [CrossRef] [PubMed]

65. Wirth, B.; Mendoza-Ferreira, N.; Torres-Benito, L. Chapter 12-Spinal muscular atrophy disease modifiers. In Spinal Muscular Atrophy: Disease Mechanisms and Therapy; Academic Press: Amsterdam, The Netherlands, 2017; pp. 191-210. 
66. Pedrotti, S.; Bielli, P.; Paronetto, M.; Ciccosanti, F.; Fimia, G.; Stamm, S.; Manley, J.; Sette, C. The splicing regulator Sam68 binds to a novel exonic splicing silencer and functions in SMN2 alternative splicing in spinal muscular atrophy. EMBO J. 2010, 29, 1235-1247. [CrossRef] [PubMed]

67. Powis, R.A.; Karyka, E.; Boyd, P.; Côme, J.; Jones, R.A.; Zheng, Y.; Szunyogova, E.; Groen, E.J.; Hunter, G.; Thomson, D.; et al. Systemic restoration of UBA1 ameliorates disease in spinal muscular atrophy. JCI Insight 2016, 1, e87908. [CrossRef] [PubMed]

68. Zheleznyakova, G.; Nilsson, E.; Kiselev, A.; Maretina, M.; Tishchenko, L.; Fredriksson, R.; Baranov, V.; Schiöth, H. Methylation levels of SLC23A2 and NCOR2 genes correlate with spinal muscular atrophy severity. PLoS ONE 2015, 10, e0121964. [CrossRef]

69. Branchu, J.; Biondi, O.; Chali, F.; Collin, T.; Leroy, F.; Mamchaoui, K.; Makoukji, J.; Pariset, C.; Lopes, P.; Massaad, C.; et al. Shift from extracellular signal-regulated kinase to AKT/cAMP response element-binding protein pathway increases survival-motorneuron expression in spinal-muscular-atrophy-like mice and patient cells. J. Neurosci. 2013, 33, 4280-4294. [CrossRef]

70. Riessland, M.; Kaczmarek, A.; Schneider, S.; Swoboda, K.J.; Löhr, H.; Bradler, C.; Grysko, V.; Dimitriadi, M.; Hosseinibarkooie, S.; Torres-Benito, L.; et al. Neurocalcin Delta Suppression Protects against Spinal Muscular Atrophy in Humans and across Species by Restoring Impaired Endocytosis. Am. J. Hum. Genet. 2017, 100, 297-315. [CrossRef]

71. Little, D.; Valori, C.F.; Mutsaers, C.A.; Bennett, E.J.; Wyles, M.; Sharrack, B.; Shaw, P.J.; Gillingwater, T.H.; Azzouz, M.; Ning, K. PTEN Depletion Decreases Disease Severity and Modestly Prolongs Survival in a Mouse Model of Spinal Muscular Atrophy. Mol. Ther. 2015, 23, 270-277. [CrossRef]

72. Helmken, C.; Hofmann, Y.; Schoenen, F.; Oprea, G.; Raschke, H.; Rudnik-Schöneborn, S.; Zerres, Z.; Wirth, B. Evidence for a modifying pathway in SMA discordant families: Reduced SMN level decreases the amount of its interacting partners and Htra2-beta1. Hum. Genet. 2003, 114, 11-21. [CrossRef]

73. Soler-Botija, C.; Ferrer, I.; Alvarez, J.; Baiget, M.; Tizzano, E. Downregulation of Bcl-2 proteins in type I spinal muscular atrophy motor neurons during fetal development. J. Neuropathol. Exp. Neurol. 2003, 62, 420-426. [CrossRef]

74. Farooq, F.; Molina, F.A.; Hadwen, J.; MacKenzie, D.; Witherspoon, L.; Osmond, M.; Holcik, M.; MacKenzie, A. Prolactin increases SMN expression and survival in a mouse model of severe spinal muscular atrophy via the STAT5 pathway. J. Clin. Investig. 2011, 121, 3050. [CrossRef] [PubMed]

75. Grondard, C.; Biondi, O.; Armand, A.-S.; Lécolle, S.; Gaspera, B.D.; Pariset, C.; Li, H.; Gallien, C.-L.; Vidal, P.-P.; Chanoine, C.; et al. Regular Exercise Prolongs Survival in a Type 2 Spinal Muscular Atrophy Model Mouse. J. Neurosci. 2005, 25, 7622. [CrossRef] [PubMed]

76. Finkel, R.S.; Mercuri, E.; Darras, B.T.; Connolly, A.M.; Kuntz, N.L.; Kirschner, J.; Chiriboga, C.A.; Saito, K.; Servais, L.; Tizzano, E.; et al. Nusinersen versus Sham Control in Infantile-Onset Spinal Muscular Atrophy. N. Engl. J. Med. 2017, 377, 1723-1732 [CrossRef] [PubMed]

77. Baranello, G.; Darras, B.T.; Day, J.W.; Deconinck, N.; Klein, A.; Masson, R.; Mercuri, E.; Rose, K.; El-Khairi, M.; Gerber, M.; et al. Risdiplam in Type 1 Spinal Muscular Atrophy. N. Engl. J. Med. 2021, 384, 915-923. [CrossRef] [PubMed]

78. Mendell, J.R.; Al-Zaidy, S.; Shell, R.; Arnold, W.D.; Rodino-Klapac, L.R.; Prior, T.W.; Lowes, L.; Alfano, L.; Berry, K.; Church, K.; et al. Single-Dose Gene-Replacement Therapy for Spinal Muscular Atrophy. N. Engl. J. Med. 2017, 377, 1713-1722. [CrossRef]

79. Lee, B.H.; Collins, E.; Lewis, L.; Guntrum, D.; Eichinger, K.; Voter, K.; Abdel-Hamid, H.Z.; Ciafaloni, E. Combination therapy with nusinersen and AVXS-101 in SMA type 1. Neurology 2019, 93, 640-641. [CrossRef]

80. Matesanz, S.E.; Curry, C.; Gross, B.; Rubin, A.I.; Linn, R.; Yum, S.W.; Kichula, E.A. Clinical Course in a Patient With Spinal Muscular Atrophy Type 0 Treated With Nusinersen and Onasemnogene Abeparvovec. J. Child Neurol. 2020, 35, 717-723. [CrossRef]

81. Harada, Y.; Rao, V.K.; Arya, K.; Kuntz, N.L.; DiDonato, C.J.; Napchan-Pomerantz, G.; Agarwal, A.; Stefans, V.; Katsuno, M.; Veerapandiyan, A. Combination molecular therapies for type 1 spinal muscular atrophy. Muscle Nerve 2020, 62, 550-554. [CrossRef]

82. Van Alstyne, M.; Tattoli, I.; Delestrée, N.; Recinos, Y.; Workman, E.; Shihabuddin, L.; Zhang, C.; Mentis, G.; Pellizzoni, L. Gain of toxic function by long-term AAV9-mediated SMN overexpression in the sensorimotor circuit. Nat. Neurosci. 2021, 24, 930-940. [CrossRef]

83. Kirschner, J.; Butoianu, N.; Goemans, N.; Haberlova, J.; Kostera-Pruszczyk, A.; Mercuri, E.; van der Pol, W.L.; Quijano-Roy, S.; Sejersen, T.; Tizzano, E.F.; et al. European ad-hoc consensus statement on gene replacement therapy for spinal muscular atrophy. Eur. J. Paediatr. Neurol. 2020, 28, 38-43. [CrossRef] [PubMed]

84. Tizzano, E.F.; Finkel, R.S. Spinal muscular atrophy: A changing phenotype beyond the clinical trials. Neuromuscul. Disord. 2017, 27, 883-889. [CrossRef] [PubMed]

85. Pagliarini, V.; Guerra, M.; Di Rosa, V.; Compagnucci, C.; Sette, C. Combined treatment with the histone deacetylase inhibitor LBH589 and a splice-switch antisense oligonucleotide enhances SMN2 splicing and SMN expression in Spinal Muscular Atrophy cells. J. Neurochem. 2020, 153, 264-275. [CrossRef] [PubMed] 